\title{
Avaliação da toxicidade e da teratogenicidade do femproporex em fetos de camundongos provenientes de pais expostos à droga durante a vida intra-uterina
}

\section{Toxicity and teratogenicity evaluation of fenproporex in mice fetuses descending from parents that were exposed to this drug during intra- uterine life}

\author{
Carolina Campos Lima Moreira ${ }^{1}$; Maria José Sparça Salles de Faria²; \\ Camila Queiroz Moreira ${ }^{3}$
}

\section{Resumo}

Femproporex é um anorexígeno que se transforma em anfetamina no organismo. $\mathrm{O}$ uso de compostos anfetamínicos durante a gravidez aumenta o risco de exencefalia, de fenda palatina e de malformações cardíacas. O objetivo deste estudo foi avaliar o desenvolvimento embriofetal, a embriotoxicidade e possíveis efeitos teratogênicos em fetos de camundongos provenientes de pais que foram expostos ao femproporex durante o desenvolvimento intra-uterino. As fêmeas prenhes foram tratadas diariamente, via gavage, com $15 \mathrm{mg} / \mathrm{kg}$ de femproporex, durante toda a gestação. Quando as progênies atingiram a idade adulta, foram acasaladas com camundongos íntegros, obtendo-se a $2^{\mathrm{a}}$ geração. No $18^{\circ}$ dia de prenhez, as fêmeas foram mortas. Observou-se que o femproporex não alterou significativamente o peso da placenta, o comprimento dos fetos, a taxa de perda pós-implantação, a análise visceral e a esquelética. Isso pode ter ocorrido devido à diminuição dos efeitos da anfetamina na $2^{a}$ geração. Porém, houve diferença estatisticamente significativa em relação ao peso dos fetos. A redução do peso fetal é usada como parâmetro para evidenciar efeitos tóxicos de uma substância. Portanto, os resultados sugerem que o femproporex apresentou toxicidade fetal nas condições experimentais testadas.

Palavras-chave: Femproporex. Desenvolvimento embriofetal. Toxicidade. Teratogenicidade. $2^{\mathrm{a}}$ geração

\begin{abstract}
Fenproporex is an anorectic drug that is transformed into amphetamine in the organism. The use of amphetaminic compounds during pregnancy increases the risk of exencephaly, cleft palate and cardiac malformations. The aim of this study was to evaluate embryo-fetal development, embryotoxicity and possible teratogenic effects in mice fetuses descending from parents that were exposed to fenproporex duringintra-uterine development. Pregnant females were treated daily, by gavage, with $15 \mathrm{mg} / \mathrm{kg}$ of fenproporex during all the gestation. When the off springs reached the adult age, they were mated with
\end{abstract}

1 Graduanda do $4^{\circ}$ ano de Biomedicina. Instituição: Universidade Estadual de Londrina; Endereço Residencial: Rua Espírito Santo, 1114 - apto 1202 - CEP 86020-420 - Londrina/PR; Telefone: (43) 9911-8155; E-mail: cclm85@ yahoo.com.br.

2 Instituição: Universidade Estadual de Londrina; Endereço Residencial: Rua Prefeito Hugo Cabral, 1065 - apto 501 - CEP 86020 918 - Londrina/PR; Telefone: (43) 9122-8889; E-mail: maze@uel.br.

3 Instituição: Universidade Estadual de Londrina; Endereço Residencial: Rua Marcílio Dias, 125 - apto 1602 - CEP 86015 -620 Bairro Petrópolis - Londrina/PR; E-mail: camilaqmoreira@gmail.com. 
integral mice, obtaining the2nd generation. On the 18th gestational day, female mice were killed. It was observed that fenproporex did not alter significantly placent weight, fetuses length, rate of postimplantation loss, visceral and skeletal analysis. This may have occurred due to the decrease of the amphetamine effects on the 2nd generation. However, there was statistically significant difference in relation to the fetuses weight. The reduction of fetal weight is used as parameter to evidence toxic effects of asubstance. Therefore, the results suggest that fenproporex presented fetaltoxicity in the tested experimental conditions.

Key words: Fenproporex. Embryo-fetal development. Toxicity. Teratogenicity. $2^{\text {nd }}$ generation

\section{Introdução}

O femproporex, 3-[(1-metil-2-feniletil)amino]propano-nitrilo, é uma das inúmeras drogas anorexígenas disponíveis em vários países (SCHELESSER, 1991). O INCB (International Narcotics Control Board, 1998), considera o uso de drogas anorexígenas um dos principais problemas na América do Sul, sendo o Brasil, Argentina e Chile os países mais afetados.

Os países em desenvolvimento, como o Brasil, apresentam precárias informações acerca dos potenciais riscos tóxicos e teratogênicos de substâncias químicas. Estima-se que um ser humano possa estar exposto a aproximadamente 5 milhões de diferentes substâncias químicas, das quais cerca de apenas 1.500 foram testadas em animais, e pouco mais de 40 são comprovadamente teratogênicas ao homem (SHEPARD, 1992).

O femproporex é um agente simpatomimético com efeitos similares àqueles da dextro-anfetamina (BELL et al., 2001) e é rapidamente biotransformado em pelo menos 14 metabólitos, sendo a anfetamina um desses compostos (KRAEMER et al., 2000).

Após a administração de femproporex, altos níveis de anfetamina aparecem no cérebro de ratos e urina de humanos (TOGNONI; MORSELLI; GARATTINI, 1972), pois ele é transformado em anfetamina no organismo humano (KRAEMER et al., 2000), através da clivagem da ligação nitrogênio-cianoetil. Sendo assim, o femproporex pode produzir os mesmos efeitos adversos da anfetamina como agitação, euforia, tremor, hiperreflexia, irritabilidade, confusão, agressividade e pânico, os quais, geralmente, são acompanhados por fadiga e depressão.
Sussman (1963) demonstrou que a anfetamina atravessa a barreira placentária e pode concentrarse nos tecidos fetais (GARRIOTT; SPRUILL, 1973; BOST; KEMP; HNILICA, 1989). O uso de compostos anfetamínicos em humanos, durante os primeiros meses de gravidez, está associado ao aumento do risco de malformações congênitas, incluindo malformações cardíacas (GILBERT; KHOURY, 1970; NORA et al., 1970), exencefalia (MATERA; ZABARA; JIMENEZ, 1968) e atresia biliar (LEVIN, 1971). Em um estudo prospectivo, Milkovitch e Van Der Berg (1977) mostraram que o uso materno dessa droga aumenta o risco de fenda palatina. Kandall (1991) relatou que as anfetaminas causam vasoconstrição e hipertensão, o que pode resultar em hipóxia fetal aguda ou crônica.

Poucos estudam o potencial toxicológico e teratogênico do femproporex, por esta razão, realizou-se este trabalho com o objetivo de investigar o desenvolvimento embriofetal, avaliar a embriotoxicidade e os possíveis efeitos teratogênicos em fetos de camundongos provenientes de pais que foram expostos ao femproporex, durante o desenvolvimento intra-uterino.

\section{Materiais e métodos}

Neste experimento foram utilizados camundongos machos e fêmeas da linhagem Swiss, provenientes de mães tratadas com femproporex durante a gestação. Estes animais foram provenientes do Biotério Central da Universidade Estadual de Londrina - UEL e abrigados em gaiolas de polipropileno, com serragem e livre acesso a alimentação e água. Foram mantidos em um ambiente 
com temperatura controlada $\left(22 \pm 2{ }^{\circ} \mathrm{C}\right) \mathrm{e}$ luminosidade de 12:12 horas claro:escuro.

As fêmeas prenhes foram tratadas, por gavage, com femproporex diluído em água destilada, enquanto o grupo controle foi tratado somente com água destilada, diariamente do 0 ao $19^{\circ}$ dia de gestação. A dose administrada foi baseada em seus pesos, sendo esta de $15 \mathrm{mg} / \mathrm{kg}$ do animal. Estudos preliminares no nosso laboratório e dados da literatura (MATTEI; CARLINI, 1996) mostraram que a dose de $20 \mathrm{mg} /$ $\mathrm{kg}$ debilita a saúde do animal, desse modo a dose escolhida foi de $15 \mathrm{mg} / \mathrm{kg}$.

Esperou-se que as proles nascessem normalmente e atingissem 60 dias, para que fossem acasaladas com camundongos íntegros (que não foram expostos ao femproporex durante seu desenvolvimento intra-uterino).

Acasalaram-se, portanto, machos provenientes de mães tratadas com fêmeas íntegras, fêmeas provenientes de mães tratadas com machos íntegros, machos íntegros com fêmeas íntegras (grupo controle). A prenhez foi determinada na manhã seguinte pela presença de "rolha" (líquido seminal) na vagina das fêmeas. O dia em que foi verificada a rolha foi caracterizado como dia zero de prenhez e, a partir dele, as matrizes foram pesadas de três em três dias.

No $18^{\circ}$ dia de prenhez, as fêmeas foram mortas por deslocamento cervical e foi realizada a laparotomia, na qual foram registrados os seguintes dados: número de implantações, peso médio dos fetos de cada ninhada, peso médio das placentas de cada ninhada e média da medida topo da cabeça-nádega dos fetos de cada ninhada. A partir desses dados, calculou-se a taxa de crescimento intra-uterino e a taxa de perda pós- implantação $\left(\mathrm{n}^{\mathrm{o}}\right.$ de implantações $-\mathrm{n}^{\mathrm{o}}$ de fetos vivos $\mathrm{x}$ $100 / n^{\circ}$ de implantações) com o intuito de avaliar a toxicidade embriofetal. O número de implantações foi determinado pelo método de Salewski (1964). Além disso, os fetos da $2^{\mathrm{a}}$ geração após o tratamento com femproporex foram avaliados para malformações externas e analisados esquelética e visceralmente, a fim de se verificar a teratogenicidade embriofetal.

Para a realização da análise visceral, os fetos foram fixados em solução de Bodian, segundo os protocolos de Wilson (1965) e Barrow e Taylor (1969). Após esse período, eles foram examinados pela combinação cortes/microdissecção, sendo estas avaliações executadas sob lupa microscópica.

Os fetos submetidos à análise esquelética foram fixados em acetona, eviscerados, clareados com hidróxido de potássio e corados com alizarina, conforme Staples e Schnell (1964).

A interpretação estatística do crescimento intrauterino foi analisada por meio do teste t de Student, no nível de significância de p d" 0,05. A taxa de perda pós-implantação foi analisada pelo teste de MannWhitney, e as análises esquelética e visceral foram analisadas pelo teste de Kruskal-Wallis.

\section{Resultados}

Os resultados obtidos demonstraram que não houve diferença estatisticamente significativa em relação às seguintes variáveis: peso de placenta (Tabela 1), comprimento dos fetos (Tabela 1), taxa de perda pósimplantação (Tabela 2), análise visceral (Tabela 3) e esquelética (Tabela 4). Contudo, os resultados mostraram que o femproporex alterou significativamente o peso dos fetos, $\mathrm{p}=0,0452$ (Tabela 1$)$.

Tabela 1. Efeito do tratamento de femproporex no crescimento intra-uterino

\begin{tabular}{cccc}
\hline & MT x FI & FT x MI & FI x MI \\
\hline N $^{\text {de amostras (mães) }}$ & 14 & 11 & 11 \\
Peso de placenta (g) & $0,067 \pm 0,020$ & $0,068 \pm 0,014$ & $0,076 \pm 0,023$ \\
Comprimento de fetos (cm) & $2,546 \pm 0,170$ & $2,491 \pm 0,104$ & $2,591 \pm 0,138$ \\
*Peso de fetos (g) & $1,384 \pm 0,209^{\mathrm{a}}$ & $1,324 \pm 0,123^{\mathrm{a}}$ & $1,439 \pm 0,129^{\mathrm{b}}$ \\
\hline
\end{tabular}

Dados apresentados como média \pm desvio padrão. (Teste t-student, $\mathrm{p} £$ 0,05). Médias seguidas por letras diferentes são estatisticamente diferentes. MT: macho proveniente de mãe tratada, FT: fêmea proveniente de mãe tratada, MI: macho íntegro, FI: fêmea íntegra *Alteração significante $(\mathrm{p}=0,0452)$ 
Tabela 2. Efeito do tratamento de femproporex na taxa de perda pós-implantação

\begin{tabular}{cccc}
\hline & MT x FI & FT x MI & FI x MI \\
\hline $\mathrm{N}^{\circ}$ de amostras (mães) & 14 & 12 & 11 \\
Taxa de perda pós-implantação (\%) & 20,45 & 13,63 & 23,35 \\
\hline
\end{tabular}

(Teste Mann-Whitney). Não houve diferença estatisticamente significativa entre os grupos. MT: macho proveniente de mãe tratada, FT: fêmea proveniente de mãe tratada, MI: macho íntegro, FI: fêmea íntegra

Tabela 3. Efeito do tratamento de femproporex na análise visceral

\begin{tabular}{|c|c|c|c|}
\hline & MT x FI & FT $\times$ MI & FI x MI \\
\hline $\mathrm{N}^{\circ}$ de amostras (mães) & 13 & 10 & 10 \\
\hline $\begin{array}{c}\text { Alterações e/ou } \\
\text { malformações da cabeça }\end{array}$ & $10,52 \pm 27,75$ & $7,36 \pm 11,58$ & $2 \pm 6,33$ \\
\hline $\mathrm{N}^{\circ}$ de amostras (mães) & 13 & 10 & 10 \\
\hline $\begin{array}{c}\text { Alterações e/ou } \\
\text { malformações do pescoço }\end{array}$ & $0 \pm 0$ & $1,67 \pm 5,28$ & $0 \pm 0$ \\
\hline $\mathrm{N}^{\circ}$ de amostras (mães) & 13 & 10 & 10 \\
\hline $\begin{array}{c}\text { Alterações e/ou } \\
\text { malformações do tórax }\end{array}$ & $4,95 \pm 14,10$ & $7,34 \pm 13,41$ & $0 \pm 0$ \\
\hline $\mathrm{N}^{\circ}$ de amostras (mães) & 13 & 10 & 10 \\
\hline $\begin{array}{c}\text { Alterações e/ou } \\
\text { malformações do Abdome }\end{array}$ & $1,54 \pm 5,55$ & $9,25 \pm 12,29$ & $3,67 \pm 7,78$ \\
\hline
\end{tabular}

Dados apresentados como média \pm desvio padrão. (Teste Kruskal-Wallis, $\mathrm{p} \leq 0,05$ ). Não houve diferença estatisticamente significativa entre os grupos. MT: macho proveniente de mãe tratada, FT: fêmea proveniente de mãe tratada, MI: macho íntegro, FI: fêmea íntegra

Tabela 4. Efeito do tratamento de femproporex na análise esquelética

\begin{tabular}{|c|c|c|c|}
\hline & MT x FI & FT x MI & FI x MI \\
\hline $\mathrm{N}^{\circ}$ de amostras (mães) & 11 & 10 & 13 \\
\hline $\begin{array}{l}\text { Alterações e/ou } \\
\text { malformações do crânio }\end{array}$ & $12,5 \pm 30,10$ & $3,67 \pm 7,78$ & $1,54 \pm 5,55$ \\
\hline $\mathrm{N}^{\mathrm{o}}$ de amostras (mães) & 11 & 10 & 8 \\
\hline $\begin{array}{l}\text { Alterações e/ou } \\
\text { malformações do tronco }\end{array}$ & $36,21 \pm 28,83$ & $42,04 \pm 33,21$ & $17,6 \pm 18,17$ \\
\hline $\mathrm{N}^{\mathrm{o}}$ de amostras (mães) & 10 & 10 & 8 \\
\hline $\begin{array}{c}\text { Alterações e/ou } \\
\text { malformações da cintura } \\
\text { escapular }\end{array}$ & $10 \pm 31,62$ & $0 \pm 0$ & $0 \pm 0$ \\
\hline $\mathrm{N}^{\mathrm{o}}$ de amostras (mães) & 10 & 10 & 8 \\
\hline $\begin{array}{c}\text { Alterações e/ou } \\
\text { malformaçóes da cintura } \\
\text { pélvica }\end{array}$ & $10 \pm 31,62$ & $0 \pm 0$ & $0 \pm 0$ \\
\hline
\end{tabular}

Dados apresentados como média \pm desvio padrão. (Teste Kruskal-Wallis, $\mathrm{p} \leq 0,05$ ). Não houve diferença estatisticamente significativa entre os grupos. MT: macho proveniente de mãe tratada, FT: fêmea proveniente de mãe tratada, MI: macho íntegro, FI: fêmea íntegra 
Foram observadas algumas alterações nas análises esquelética e visceral. $\mathrm{Na}$ análise visceral foram encontrados: coração globoso, alteração de esôfago, fenda palatina (Figura 1), $4^{\circ}$ ventrículo aumentado, e rins de tamanho diminuído (Figura 2) e com forma alterada. $\mathrm{Na}$ análise esquelética, foram encontrados: crânio com ossificação reduzida, fontanela aberta (Figura 3), fissura interparietal aumentada, 14 ${ }^{\mathrm{a}}$ costela cervical extra, 14 ${ }^{\mathrm{a}}$ costela cervical rudimentar, ausência de esterno, esterno com menos de 6 esternébrios, esternébrios assimétricos, esternébrios em borboleta (Figura 4), esternébrios irregulares e esternébrios bifurcados.

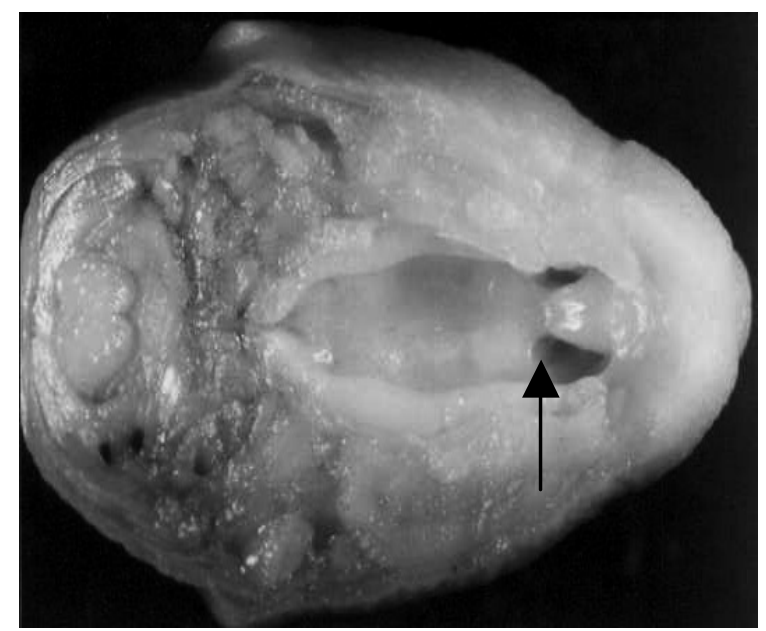

Figura 1. Fenda palatina (seta)

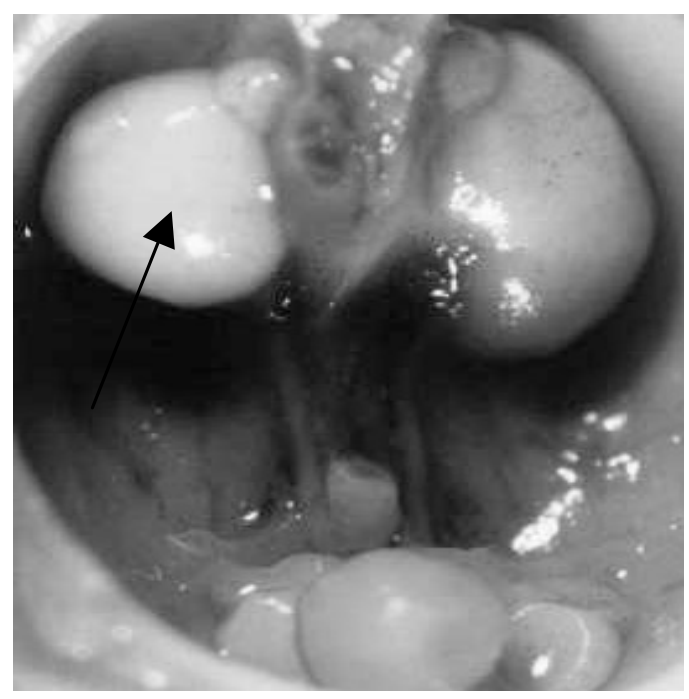

Figura 2. Rim com tamanho diminuído (seta)

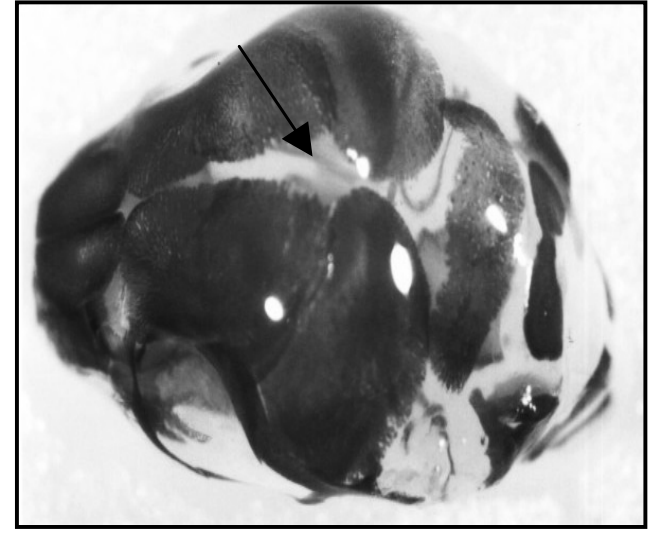

Figura 3. Vista superior do crânio com fontanela aberta (seta)

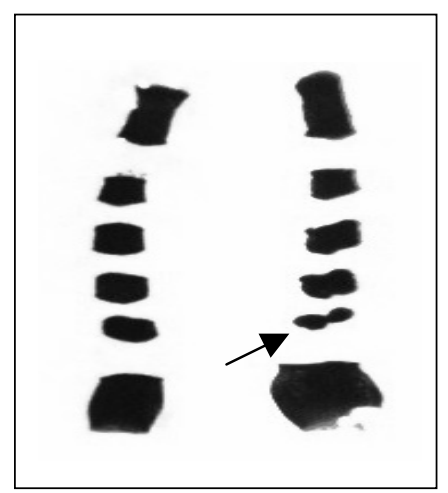

Figura 4. Esterno normal e $5^{\circ}$ esternébrio em borboleta (seta)

\section{Discussão}

Em relação à variável peso de placenta, não houve diferença estatisticamente significativa entre as fêmeas que foram expostas ao femproporex durante a vida intra-uterina e as fêmeas que não foram expostas. Porém, dados de Moreira et al. (2005) demonstraram que camundongos fêmeas que foram tratados com femproporex, via gavage, durante o período gestacional, apresentaram o peso das placentas significantemente menor nos animais tratados por longos períodos.

Quanto ao comprimento dos fetos, não houve alteração significativa. Em um estudo conduzido por Cui et al. (2006), no qual ratas prenhes foram tratadas com metanfetamina durante o $10^{\circ}$ ao $20^{\circ}$ dia gestacional, o comprimento médio da ninhada também não foi afetado pela droga. Porém, segundo Yamamoto et al. (1998), embriões de ratos expostos 
"in vitro" à anfetamina têm seus comprimentos significativamente diminuídos.

$\mathrm{O}$ femproporex alterou significativamente o peso dos fetos da $2^{\mathrm{a}}$ geração. Um estudo realizado por Buttar, Moffatt e Foster (1996) demonstrou também uma significativa redução do peso de fetos expostos, durante sua vida intra-uterina, à anfetamina. AcuffSmith et al. (1996) também mostraram que ratos têm seus pesos diminuídos quando expostos à metanfetamina no período tardio da gestação. A redução do peso fetal é usada como uma evidência dos efeitos tóxicos de uma substância recebida durante a gravidez.

A perda pós-implantação não foi estatisticamente significativa em mães expostas ao femproporex, durante a vida intra-uterina. Esse mesmo quadro foi observado por Moreira et al. (2005) em mães que foram tratadas com femproporex no período de prenhez.

O femproporex não alterou significativamente a análise visceral e a análise esquelética, contrastando com um estudo prévio realizado por Yamamoto et al. (1992), segundo o qual uma única injeção de anfetamina intraperitoneal no $18^{\circ}$ dia de gravidez causou exencefalia, malformação de pálpebras e anomalias de costela nos fetos da $1^{\mathrm{a}}$ geração. $\mathrm{O}$ fato de o femproporex não alterar a análise visceral nem a esquelética pode ser devido à atenuação dos efeitos da anfetamina na $2^{\mathrm{a}}$ geração. Os resultados indicam que o femproporex, na dose estudada, afetou o desenvolvimento embriofetal de camundongos da $2^{\mathrm{a}}$ geração, devido à alteração do peso fetal. Pode-se concluir que o femproporex é um agente com potencial tóxico para este delineamento experimental.

\section{Referências}

ACUFF-SMITH, K. D.; SCHILLING, M. A.; FISHER, J. E.; VORHEES, C. V. Stage-specific effects of prenatal dmethamphetamine exposure on behavioral and eye development in rats. Neurotoxicology Teratology, Oxford, v.18, p.199-215, 1996.
BARROW, M. V.; TAYLOR, W. J. A rapid method for detecting malformations in rat fetuses. Journal of. Morphology, New York, v.127, p.291-306, 1969.

BELL, R. R.; CROOKHAM, S. B.; DUNN, W. A.; GRATES, K. M.; REIBER, T. M. A contemporaneous finding of fenproporex in a polydrug suicide. Journal Of Analytical Toxicology, Niles, v.25, n.7, p.652-656, Oct.2001.

BOST, R. O.; KEMP, P.; HNILICA V. Tissue distribution of methamphetamine and amphetamine in premature infants. Journal Of Analytical Toxicology, Niles, v.13, n.5, p.300302, Sep./Oct.1989.

BUTTAR, H. S.; MOFFATT, J. H.; FOSTER, B. C. Developmental toxicity of 4-substituted amphetamines in mice. Reproductive Toxicology, Kidlington-Oxford, v.10, n.4, p.301-310, 1996.

CUI, C.; SAKATA-HAGA, H.; OHTA, K.; NISHIDA, M.; YASHIKI, M.; SAWADA, K.; FUKUI, Y. Histological brain alterations following prenatal methamphetamine exposure in rats. Congenital Anomalies, Oxford, v.46, n.4, p.180187, Dec.2006.

GARRIOT, J. C.; SPRUILL, F. G. Detection of methamphetamine in a newborn infant. Journal of Forensic Sciences, Philadelphia, v.18, n.4, p.434-436, Oct.1973.

GILBERT, E. F.; KHOURY, G. H. Dextroamphetamine and congenital cardiac malformations. Journal of. Pediatrics, St Louis, v.76, n.4, p.638, Apr.1970.

INTERNATIONAL NARCOTICS CONTROL BOARD INCB. Report of international narcotics control board for 1998. New York: United Nations; 1999.

KANDALL, S. R. Perinatal effects of amphetamine use during pregnancy. Bulletin of the New York Academy of Medicine, New York, v.67, n.3, p.240-255, May-Jun.1991.

KRAEMER, T.; THEIS, G. A.; WEBER, A. A.; MAURER, H. $\mathrm{H}$. Studies on the metabolism and toxicological detection of amphetamine-like anorectic fenproporex in human urine by gas chromatography-mass spectrometry and fluorescence polarization immunoassay. Journal of Chromatography B, Amsterdam, v.738, n.1, p.107-118, Jan.2000.

LEVIN, J. N. Amphetamine ingestion with biliary atresia. Journal of Pediatrics, St Louis, v.79, n.1, p.130-131, 1971.

MATERA, R. F.; ZABARA, H.; JIMENEZ, A. P. Bifid exencephalia: teratogen action of amphetamine. International Surgery, Padova, v.50, p.79-85, 1968.

MATTEI, R.; CARLINI, E. A. A comparative study of the anorectic and behavioural effects of fenproporex on male and female rats., Brazilian Journal Of Medical And Biological Research, Ribeirão Preto, v.29, n.8, p.1025-1030, Aug.1996. 
MOREIRA, C. Q.; FARIA, M. J. S. S.; BARONEZA, J. E.; OLIVEIRA, R. J.; MOREIRA, E. G. Developmental exposure to fenproporex: reproductive and morphological evaluation. Human \& Experimental Toxicology, London, v.24, n.8, p.397-402, Aug.2005.

MILKOVITCH, L.; VAN DER BERG, B. J. Effects of antenatal exposure to anoretic drugs. American Journal of Obstetrics and Gynecology, St Louis, v.129, p.637-642, 1977.

NORA, J. J.; VARGO, T. A; NORA, A. H.; LOVE, K. E.; MCNAMARA, D. G. Dexamphetamine: a possible environmental trigger in cardiovascular malformations. The Lancet, London, v.295, n.7659, p.1290-1291, Jun.1970

SALEWSKI, E. Färbemethoden zum makroskopischen Nachweis von Implantationsstellen am Uterus der Ratte. Naunym-Schmiedeberg Archives of Pharmakology, Berlin, v.247, n.4, p.367. 1964

SCHELESSER, J. L. Drugs available abroad: A guide to therapeutic drugs available and approved outside the U.S. Detroit: MEDEX Books, 1991.

SHEPARD, T. H. Catalog of teratogenic agents, 7. ed. Baltimore: The Johns Hopkins University Press, 1992.

STAPLES, R. E.; SCHNELL, V. L. Refinements in rapid clearing technic in the $\mathrm{KOH}$-alizarin red $\mathrm{S}$ method for fetal bone. Stain Technology, Baltimore, v.39, n.1, p.61-63, 1964.
SUSSMAN, S. Narcotic and methamphetamine use during pregnancy. Effect on newborn infants. American Journal of Diseases of Children, Chicago, v.106, n.3, p.325-330, 1963.

TOGNONI, G.; MORSELLI, P. L.; GARATTINI, S. Amphetamine concentrations in the rat brain and human urine after fenproporex administration. European Journal of Pharmacology, Amsterdam, v.20, n.1, p.125-126, 1972.

WILSON, J. G. Methods for administering agents and detecting malformations in experimental animals. In: WILSON, J. G.; WARKANY, J. Teratology: principles and techniques. Chicago: University of Chicago Press, 1965. p. 262-277.

YAMAMOTO, Y.; YAMAMOTO, K.; FUKUI, Y.; KURISHITA, A. Teratogenic effects of methamphetamine in mice. Japanese Journal of Legal Medicine - Nihon Hoigaku Zasshi, Tokyo,

v.46, n.2, p.126-131, Apr.1992.

YAMAMOTO, Y.; YAMAMOTO, K.; HAYASE, T.; FUKUI, Y.; SHIOTA, K. Effects of amphetamine on rat embryos developing in vitro. Reproductive Toxicology Kidlington, v.12, n.2, p.133-137, Mar./Apr.1998. 
